Metal-Catalyzed Asymmetric

Synthesis and

Stereoselective

Reactions

\section{Key Words}

copper(II) bis(oxazoline)

Friedel-Crafts

indoles

pyrroles

C. PALOMO,* M. OIARBIDE, B. G. KARDAK, J. M. GARCIA, A. LINDEN (UNIVERSIDAD DEL PAÍS VASCO, SAN SEBASTIÁN, SPAIN)

Highly Enantioselective Friedel-Crafts Alkylations of Pyrroles and Indoles with $\alpha^{\prime}$-Hydroxy Enones under $\mathrm{Cu}(\mathrm{II})$ -

Simple Bis(oxazoline) Catalysis

J. Am. Chem. Soc. 2005, 127, 4154-4155.

\title{
Enantioselective Friedel-Crafts Alkylations of Pyrroles and Indoles via $\alpha^{\prime}$-Hydroxyenones
}

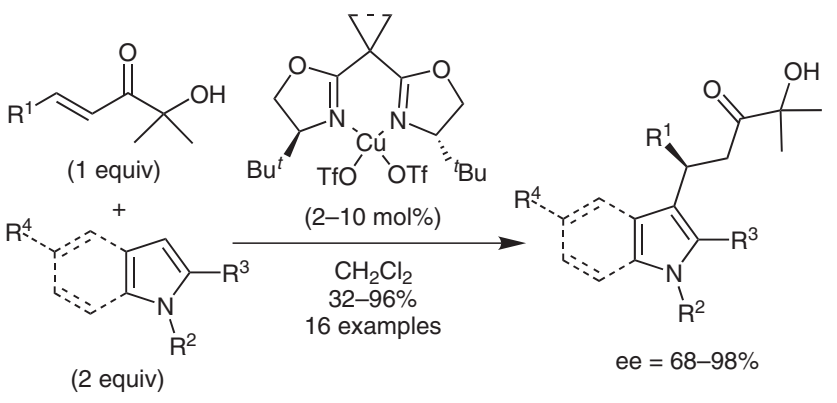

Significance: The Friedel-Crafts reaction is of great value in organic synthesis. In terms of metalcatalyzed Friedel-Crafts alkylations, there are few examples demonstrating high enantioselectivity. In many of the reported cases, strongly coordinating bidentate Michael acceptors are required for good enantiocontrol. Presented herein, non-enolizable $\alpha^{\prime}$-hydroxyenones represent the above characteristics and, in the presence of easily accessible tert-butyl-bis(oxazoline) $\mathrm{Cu}$ (II) complexes and electron-rich heteroaromatics, provide highly enantioenriched Friedel-Crafts alkylation products. This method is efficient with both pyrrole and indole as nucleophile, and with alkyl or aryl $\beta$-substituents.
Comment: The Cu(II)-t-BOX-enone complex makes the enone Si face accessible for nucleophilic attack. Although numerous alkyl and aryl $\beta$-substituents were tested, it is noted that aryl $\beta$-substituents resulted in a marked reduction in ee. Electron-donating substituents on the benzenoid ring of indole had no adverse effects, although electron-withdrawing substituents were not evaluated. Finally, the products of these reactions were elaborated into various examples of pyrrole- and indole-substituted aldehydes, ketones, and carboxylic acids. 